\title{
Castration Has Antihypertensive and Organoprotective Effects in Male but Not in Female Heterozygous Ren-2 Rats
}

\author{
Ivana Vaněčkováa, ${ }^{a}$ Zuzana Huskováa, ${ }^{a}$ Zdeňka Vaňourkováa,b \\ Luděk Červenka ${ }^{a-c}$ \\ ${ }^{a}$ Center for Experimental Medicine and ${ }^{\mathrm{b}}$ Cardiovascular Research Center, Institute for Clinical and Experimental \\ Medicine, and 'Department of Physiology, 2nd Faculty of Medicine, Charles University, Prague, Czech Republic
}

\section{Key Words}

Ren-2 rats · Hypertension · Sexual dimorphism $\cdot$ Age $\cdot$ Sex

hormones $\cdot$ Renin-angiotensin system

\begin{abstract}
Gender differences in the regulation of blood pressure (BP) and the contributions of the renin-angiotensin system remain controversial. We assessed the effect of castration on BP and organ damage, as well as angiotensin II (ANG II), estradiol and testosterone levels in heterozygous Ren-2 transgenic (TGR) rats and transgene-negative Hannover SpragueDawley control rats. Male TGR had severe hypertension throughout the experiment, while the BP of female TGR declined after 5 months to normotensive levels. Ovariectomy had no effect on BP, cardiac hypertrophy or proteinuria in female Ren-2 TGR. On the contrary, BP and cardiac hypertrophy were significantly reduced in castrated male TGR as compared to sham-operated TGR. Moreover, proteinuria in these animals was normalized to the levels of control rats. ANG II levels did not differ between male and female TGR, and no effect of castration on plasma and tissue ANG II levels was found either in male or female TGR at the end of the ex-
\end{abstract}

periment. In conclusion, the contribution of the renin-angiotensin system to the gender difference in BP homeostasis seems to be negligible in aging heterozygous Ren-2 transgenic rats.

Copyright $\odot 2010$ S. Karger AG, Basel

\section{Introduction}

Results from animal studies suggest that sex steroids play a pivotal role in various cardiovascular diseases, such as autoimmune glomerulonephritis, hypertensive glomerulosclerosis and polycystic kidney disease [1]. Men are more susceptible to these diseases, progress to endstage renal disease faster than women and have higher blood pressure (BP) than women at similar ages [2]. However, the situation substantially changes after menopause, i.e. BP in women increases to levels even higher than in men.

For women, a relative protection against cardiovascular diseases was ascribed to the beneficial effects of estrogens, while male sex has been shown to be an independent risk factor for the development and progression of 
renal disease. However, the presence of androgens rather than the absence of estrogens contributes to the predisposition of men to develop CV diseases.

It is known that testosterone stimulates major vasoconstrictor, renin-angiotensin (RAS) and endothelin systems, as well as facilitates oxidative stress. Moreover, it increases proximal sodium reabsorption via an angiotensin II (ANG II)-dependent mechanism promoting hypertension and renal damage [3]. By contrast, estrogen reduces the $\mathrm{AT}_{1}$ receptor number and attenuates the responsiveness to ANG II [4]. Therefore, it is not surprising that estradiol is renoprotective and anti-inflammatory, the renoprotective effect being independent of estradiol receptor [5].

The kidneys play a crucial role in the regulation of salt and volume homeostasis. According to Guyton's theory, the pressure-natriuresis mechanism relates to the phenomenon that increased arterial pressure elicits a marked increase in sodium excretion [6]. Most forms of hypertension are characterized by a shift of the pressure-natriuresis curve to the right. Reckelhoff [7] demonstrated a rightward shift of the pressure-natriuresis relationship in males as compared to female spontaneously hypertensive rats (SHR), with restoration of the pressure-natriuresis relationship after castration. The same effect is seen in ovariectomized females with testosterone supplementation, which suggests that androgens could have a direct effect on sodium reabsorption.

It is known that there is sexual dimorphism in the course of hypertension in transgenic rats (TGR) [8-12]. The still unanswered question is whether this difference is due to the difference in sexual hormones rather than the RAS system. Therefore, the first aim of this study was to analyze the influence of sex hormones on BP and organ protection (evaluated as proteinuria and cardiac hypertrophy). Second, we studied the effects of gonadectomy on these parameters with special emphasis on the plasma and tissue concentration of ANG II.

\section{Materials and Methods}

The present study was performed in accordance with guidelines and practices established by the Institute for Clinical and Experimental Medicine Animal Care and Use Committee (protocol 16/2008). All animals used in the study were housed in facilities accredited by the Czech Association of Laboratory Animal Care.

\section{Animals}

Male and female heterozygous TGR [strain name TGR(mRen2)27] and normotensive Hannover Sprague-Dawley rats (HanSD rats) as their transgene-negative controls were housed at $25^{\circ} \mathrm{C}$ under a 12-hour light/dark cycle with free access to food (normal rat chow: $0.45 \% \mathrm{NaCl}$ ) and water. All animals used in this study were bred at the Center for Experimental Medicine of the Institute for Clinical and Experimental Medicine from stock animals supplied by the Max Delbrück Center for Molecular Medicine in Berlin, Germany.

\section{Experimental Design}

Gonadectomy was performed in male and female TGR and their transgene-negative HanSD controls at the age of 28 days. Sham-operated animals served as controls. Systolic BP (SBP) was measured every 5 th day from day 32 onward using tail plethysmography (Hatteras Instruments, Cary, N.C., USA) until the end of the experiment on day 365. From the age of 80 days, 24-hour urine was collected and proteinuria was determined at 50-day intervals. At the same time points, mean arterial pressure was monitored in a separate group of anesthetized animals after $15 \mathrm{~min}$ of equilibration. At the end of the study, rats were sacrificed and plasma and tissue ANG II concentrations and organ weights were determined. The ratio of left ventricle weight (mg) to tibia length $(\mathrm{mm})$ was used as a measure of cardiac hypertrophy. Plasma, kidney and left ventricle ANG II levels were assessed by radioimmunoassay (IBL Hamburg, ED 29051) as described in detail previously [13]. Plasma was collected for hormone analysis, and estradiol and testosterone levels were determined using RIA (Diagnostic Systems Laboratories, Webster, Tex., USA).

\section{Results}

\section{Blood Pressure}

The SBP of control male (fig. 1a) and female (fig. 1b) HanSD rats was in a normotensive range throughout the entire course of the experiment, with a slow rise of the SBP during the first 2 months. Female and male TGR developed fulminant hypertension within 2-3 weeks after weaning. At the age of 5 months, a stepwise decline of the SBP to control levels in female TGR was observed, whereas the SBP of male TGR remained elevated until the end of the study. Gonadectomy had no effect on the course of hypertension in female TGR (fig. 1b), while it significantly decreased the levels of SBP in male TGR (fig. 1a). Mean arterial pressure in anaesthetized animals correlated well with SBP measured by tail plethysmography (fig. 1c and $\mathrm{d})$.

\section{End-Organ Damage}

Both female and male hypertensive heterozygous TGR had signs of cardiorenal damage, evaluated as cardiac hypertrophy and proteinuria, respectively. Left ventricular hypertrophy (fig. 2a, b) corresponded to the level of hypertension, and was significantly decreased in castrated male TGR (fig. 2a). At the age of 3 months, proteinuria was significantly increased both in male 


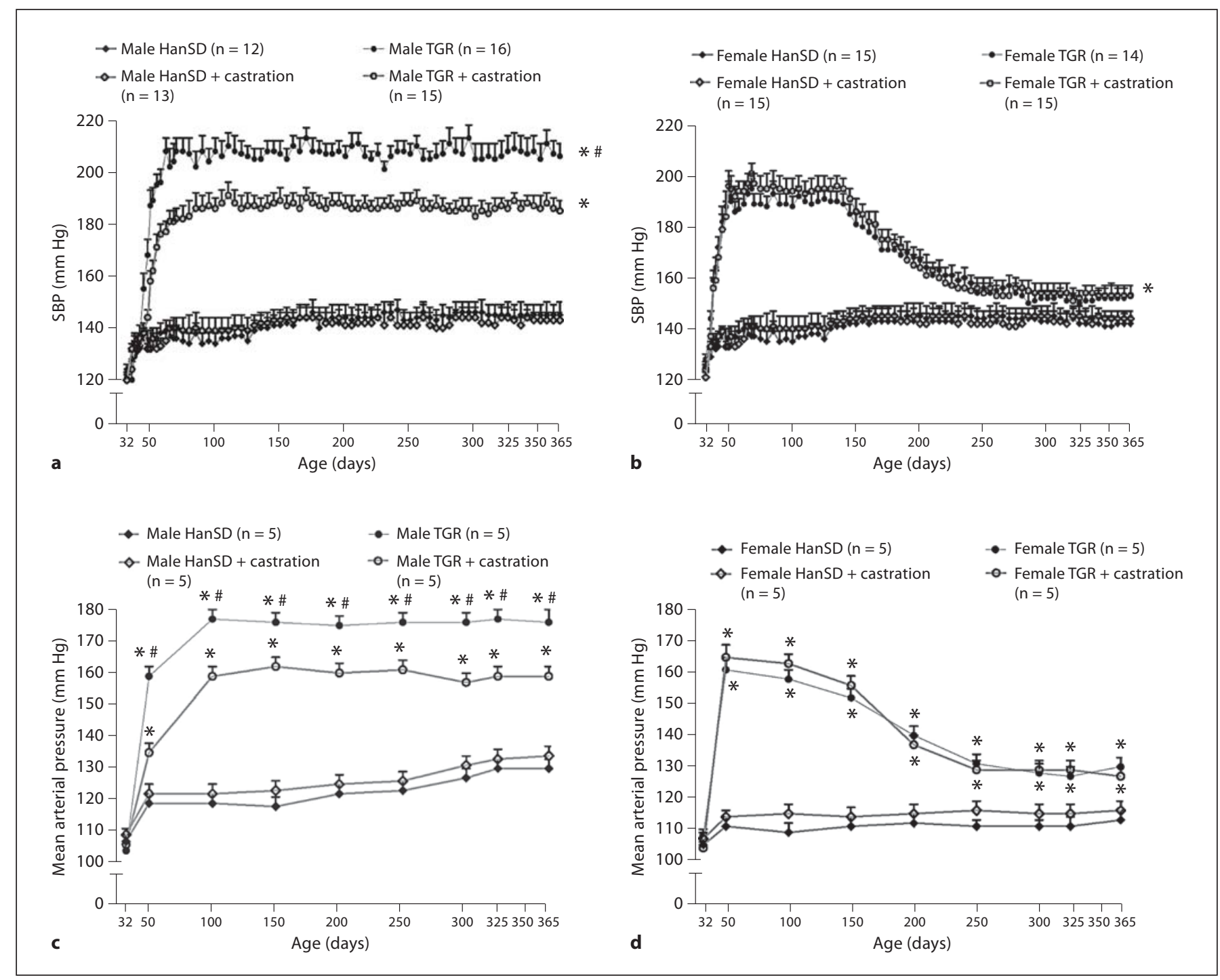

Fig. 1. a, b SBP in male and female heterozygous TGR throughout the course of the experiment. SBP of intact male TGR was significantly different from the corresponding group of HanSD rats from day $45\left({ }^{*} \mathrm{p}<0.05\right)$, and concomitantly from castrated male TGR from day $48\left({ }^{*} \mathrm{p}<0.05\right)$. SBP of female TGR groups was sig-

(fig. 2c) and in female (fig. 2d) TGR, with significantly higher levels in male TGR compared to female TGR. Increased proteinuria persisted until the age of 130 days in female TGR, at which point it declined to the control levels with no difference between noncastrated and castrated female TGR. Interestingly, castrated male TGR had normalized proteinuria throughout the whole course of the experiment, while high proteinuria was found in intact male TGR. nificantly different $\left({ }^{*} \mathrm{p}<0.05\right)$ from the corresponding groups of HanSD rats from days 38-185. c, d Mean arterial pressure in male and female heterozygous TGR throughout the course of the experiment $\left({ }^{*} p<0.05\right.$ vs. corresponding group of HanSD, ${ }^{*} p<0.05$ vs. castrated TGR).

\section{Hormone Levels}

Plasma testosterone levels were similar in male TGR and control HanSD animals (fig. 3a). In both of these groups, castration caused substantial reduction of testosterone levels to the levels of female rats. There was no difference in plasma testosterone among the 4 groups of female rats. On the other hand, plasma estradiol levels were not different in male groups (fig. 3b), while plasma estradiol levels were significantly increased in intact female HanSD rats and TGR. Ovariectomy caused a marked de- 


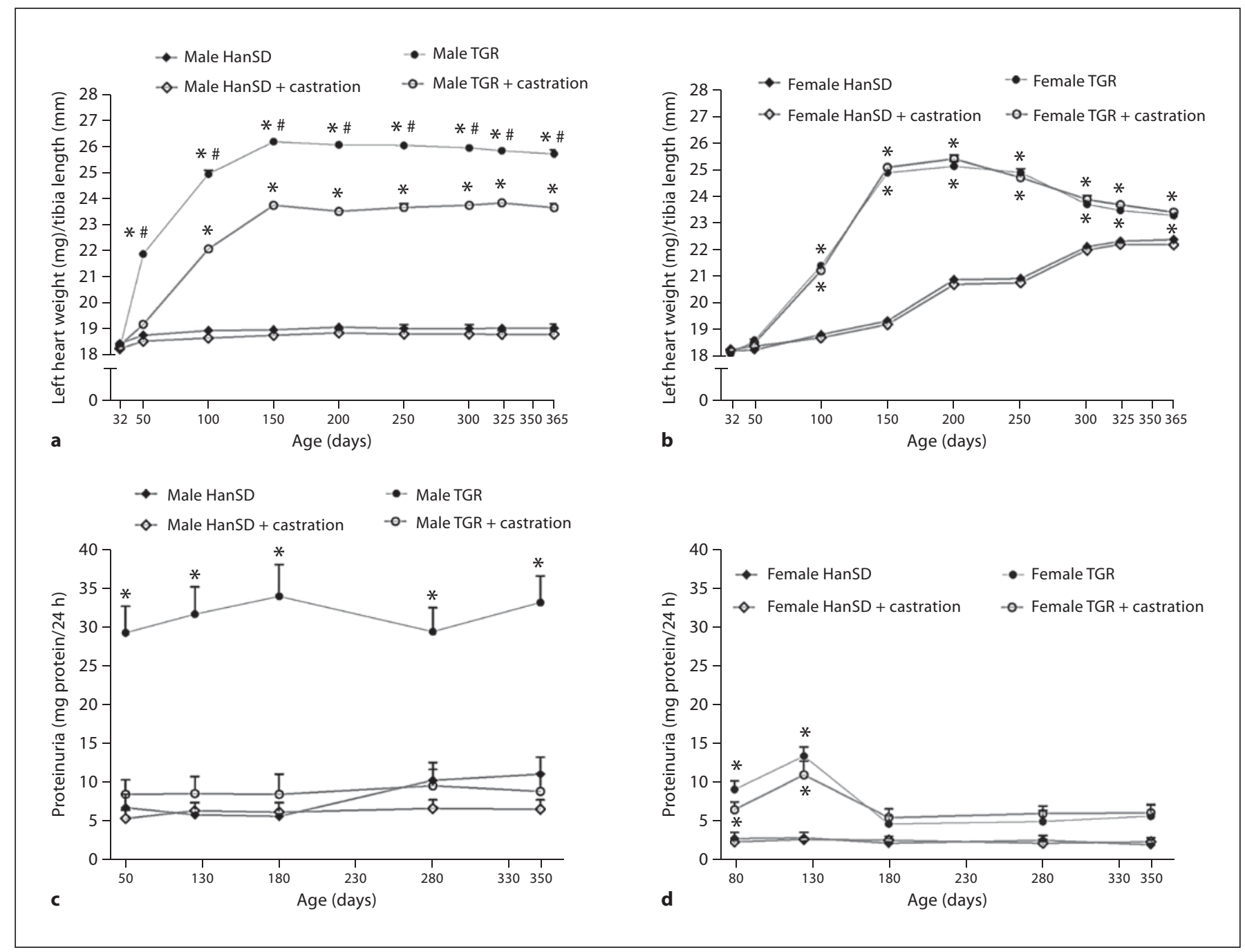

Fig. 2. Cardiac hypertrophy evaluated as left ventricle weight/tibia length and proteinuria in males (a, c) and females $(\mathbf{b}, \mathbf{d})$ throughout the course of the experiment $\left({ }^{*} \mathrm{p}<0.05\right.$ vs. corresponding group of HanSD, \# $\mathrm{p}<$ 0.05 vs. castrated TGR).

Fig. 3. Plasma testosterone (a) and estradiol (b) levels at the end of the experiment $\left({ }^{*} \mathrm{p}<0.05\right.$ vs. corresponding castrated group).

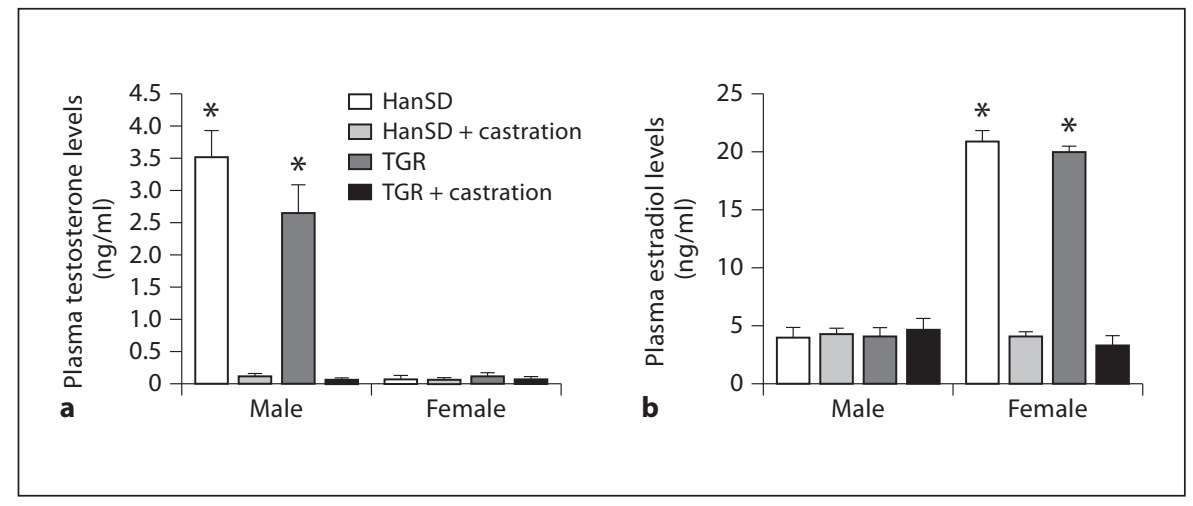

Kidney Blood Press Res 2011;34:46-52 


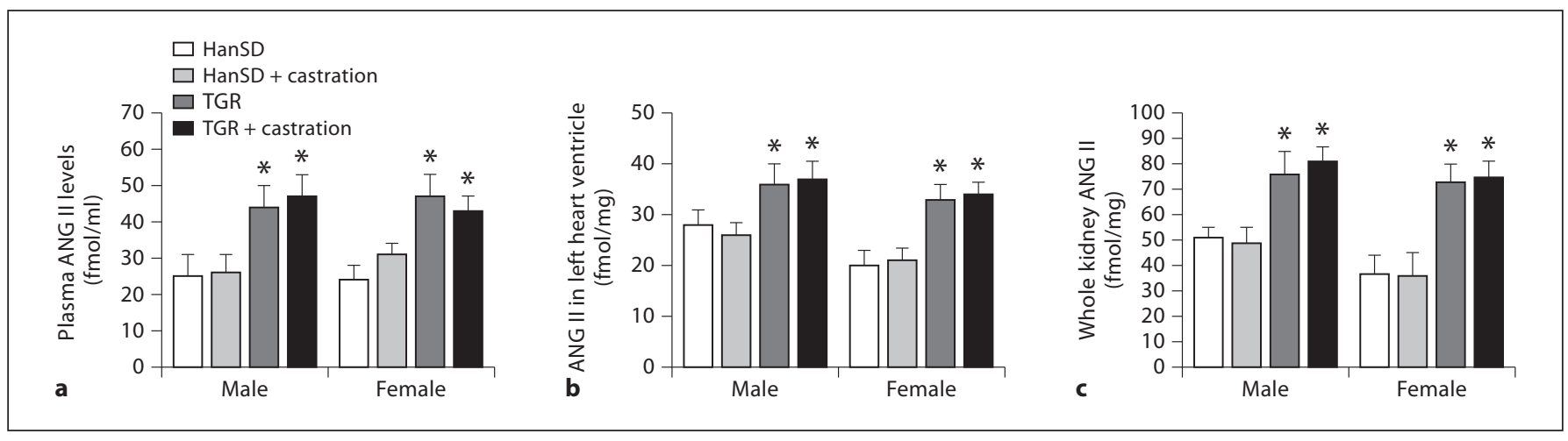

Fig. 4. Plasma (a), left ventricle (b) and whole kidney (c) ANG II levels at the end of the experiment $\left({ }^{*} \mathrm{p}<0.05\right.$ vs. corresponding group of HanSD).

crease of plasma estradiol levels, which was similar in TGR and control HanSD female groups.

Plasma (fig. 4a), left ventricular (fig. 4b) and renal (fig. 4c) ANG II levels were significantly higher in male and female TGR in comparison with control HanSD groups. No gender- or strain-dependent effects of gonadectomy on ANG II levels were found at the end of the study.

\section{Discussion}

In the present study, the increase in $\mathrm{BP}$ was attenuated in females in contrast to males. This phenomenon has been evidenced both in human and animal studies $[8,9$, $11,14]$, and is consistent with of our previous studies [15]. Moreover, there was a significant BP decrease in female TGR after the 5th month of age, a finding that has been demonstrated earlier [12]. The gradual decrease in BP with age was accompanied by the reduction of cardiac hypertrophy as seen in aging female TGR. It has been postulated that for this gender difference, the RAS [16] or interaction between the RAS and androgen receptors is responsible, as has been evidenced by the effect of antiandrogen treatment on a decrease in BP in TGR [17]. However, our results, showing no difference in ANG II levels, do not support this view.

Our study has confirmed the findings of previous studies by showing that castration of young (3- to 5-weekold) male rats attenuates the development of hypertension in various hypertensive models, i.e. SHR [18], Dahl [19] or deoxycorticosterone-salt [20]. The lack of testosterone is believed to be a key factor in these processes since blockade of the androgen receptor reduced BP in male SHR [21] and TGR [17]. On the other hand, testos- terone treatment increased BP not only in castrated male and ovariectomized female SHR [22], but also in TGR [23]. Ovariectomized female rats at the age of 5 months do not have higher BP than intact SHR females. Thus, although estrogen might be another factor in gender differences in BP regulation, the lack of testosterone rather than the presence of female hormones might be the key factor in gender BP difference. The role of testosterone seems to be more complex. Studies using cross-kidney transplantation have shown that transplantation of male kidneys to females did not result in an increase in BP. The opposite approach using transplantation of female kidneys into male rats had no BP-lowering effect, which suggests that extrarenal factors, such as androgens and not the intrinsic defect of the male kidney, might shift the pressure-natriuresis curve to the right, resulting in higher BP [24].

The possible contribution of the RAS, which has been thought to participate in gender difference in BP regulation, was not confirmed in our study. The RAS is the key system in BP regulation and many studies have shown that inappropriate activation of the RAS has led to hypertension and ultimately to end-organ damage. It has been documented that males have higher plasma renin activity [17] and $\mathrm{AT}_{1}$ receptor expression levels at both the RNA and protein levels [25]. Moreover, Rogers et al. [4] have shown that not only the receptor density, but also the specific $\mathrm{AT}_{1}$ receptor binding, is lower in glomeruli from Sprague-Dawley female rats as compared to males. Zhuo et al. [26] reported that 12-week-old male TGR have 17fold higher ANG II levels and increased $\mathrm{AT}_{1}$ receptor binding as compared to control rats. On the other hand, female SHR have higher renal $\mathrm{AT}_{2}$ gene expression and lower mRNA expression for the $\mathrm{AT}_{1}$ receptor than males. 
Ovariectomy causes upregulation of the $\mathrm{AT}_{1}$ receptor and reduction of $\mathrm{AT}_{2}$ gene expression, whereas estrogen treatment reverses these alterations [27], suggesting that female hormones also modulate the $\mathrm{AT}_{1} / \mathrm{AT}_{2}$ receptor balance. Subsequently, it was found that estrogen treatment decreases aldosterone production through $\mathrm{AT}_{1}$ receptor downregulation and $\mathrm{AT}_{2}$ receptor upregulation [28]. Finally, castration of male Sprague-Dawley rats caused increased $\mathrm{AT}_{2}$ receptor mRNA gene expression, while testosterone supplementation reduced it to control levels [29], which shows that androgens also modulate the RAS system. There is also a possibility, which cannot be ruled out, that new members of the RAS family, namely ANG (1-7), might affect the balance between vasoconstrictor and vasodilator substances influencing the final BP [30]. Surprisingly, we did not find any difference in the levels of plasma and tissue ANG II between male and female TGR or HanSD rats at the end of the study, suggesting a negligible contribution of RAS in aged TGR. However, the limitation of this statement is indicated by the fact that our results reflect the situation in 1-year-old rats, without any detailed information about the levels of RAS components during the development of hypertension. Consistent with this concept, our previous results have shown that plasma and tissue ANG II levels in male TGR tended to be lower with increasing age [31], suggesting a declining role of RAS in aging TGR. This conclusion is in agreement with Yanes et al. [32], who demonstrated that in aged 12- to 16-monthold SHR, RAS only partially contributes to hypertension.

Interestingly, we observed a continuous rise in cardiac hypertrophy (evaluated as left ventricle weight/tibia length) in female HanSD rats as compared to male HanSD rats despite their normotensive BP. This increase might reflect the fact that females retard body growth (including bones like the tibia) earlier, whereas growth is continuous throughout the whole life in males. Moreover, aging females have more fat in their bodies. If we compared the cardiac hypertrophy (evaluated as ventricle weight/body weight) at the end of the experiment, we obtain quite different results due to the fact that castration caused the loss of body weight in males, contrary to the increase of body weight in females. This phenomenon is probably connected with the effect of testosterone. On the other hand, cardiac hypertrophy remained high in female TGR despite the continuous decline in $\mathrm{BP}$, probably reflecting the late effects of originally high BP on cardiac remodeling.

Both intact and ovariectomized females exhibited a small but significant increase of proteinuria in the first 4 months of age, which corresponded to the time of increased BP in these animals with no effect of ovariecto- my. In contrast to females, intact male TGR exhibited strong proteinuria that was fully eliminated by castration, suggesting that testosterone is crucial for exerting the proteinuric effect, as has been demonstrated by Baltatu et al. $[17,33]$ using antiandrogen treatment both in male and female TGR. To further analyze the proteinuric effects of testosterone and estrogen, another set of experiments with supplementation of gonadectomized males and females with sex hormones would be desirable.

Another mechanism suggested for the increased BP in males is oxidative stress, for which ANG II has been proposed as a mediator [34]. Although Ren-2 TGR exhibit manifest hypertension, increased tissue ANG II levels and signs of oxidative stress, Kopkan et al. [35] found that the reduction of oxidative stress does not attenuate the development of hypertension in male TGR, suggesting a negligible role of oxidative stress to the development of hypertension in TGR rats.

Of particular interest is the recent study of Xue et al. [36], who provided evidence on how sex steroids affect hypertension through the modulation of the sympathetic nervous system. They found that the attenuated pressor response to ANG II in female mice is mediated via central NO and that female sex hormones together with increased nNOS play a protective role against sympathetically mediated ANG II-induced hypertension.

In conclusion, there are several important findings in our study. We demonstrated a sexual dimorphism in the course of BP in heterozygous TGR, accompanied by a gender difference in cardiac hypertrophy. Additionally, castration had a partial BP lowering effect and a profound antiproteinuric effect in males. Finally, no differences in plasma and tissue ANG II levels at the end of the experiments were found, suggesting a negligible role of the RAS system in the sex-dependent $\mathrm{BP}$ regulation in aging TGR.

\section{Acknowledgements}

We thank Mrs. Dagmar Marková and Radka Kuželková for their excellent technical assistance and Josef Zicha for his valuable comments during the preparation of the manuscript. This study was supported by grant No. 305/08/J006 awarded to L.Č. and grant No. 305/07/J004 awarded to I.V. by the Czech Science Foundation (GAČR) and by grants No. NS/10500-3 and No. NS/10499-3 by the Internal Grant Agency of the Ministry of Health of the Czech Republic. I.V. was also supported by the Center for Cardiovascular Research (1M6798582302) and by the institutional financial support of the Institute for Clinical and Experimental Medicine (MZO 00023001). This study was also supported by the financial support from the EU by the Operational Program Prague - Competitiveness; project 'CEVKOON' (No. CZ.2.16/3.1.00/22126). 


\section{References}

$\checkmark 1$ Yanes LL, Sartori-Valinotti JC, Reckelhoff JF: Sex steroids and renal disease: lessons from animal studies. Hypertension 2008;51: 976-981.

$\checkmark 2$ Silbiger S, Neugarten J: Gender and human chronic renal disease. Gend Med 2008; 5(Suppl A):S3-S10.

$\checkmark 3$ Baylis C: Age-dependent glomerular damage in the rat. Dissociation between glomerular injury and both glomerular hypertension and hypertrophy. Male gender as a primary risk factor. J Clin Invest 1994;94:1823-1829.

$\checkmark 4$ Rogers JL, Mitchell AR, Maric C, Sandberg K, Myers A, Mulroney SE: Effect of sex hormones on renal estrogen and angiotensin type 1 receptors in female and male rats. Am J Physiol Regul Integr Comp Physiol 2007; 292:R794-R799.

5 Hutchens MP, Nakano T, Kosaka Y, Dunlap J, Zhang W, Herson PS, Murphy SJ, Anderson S, Hurn PD: Estrogen is renoprotective via a nonreceptor-dependent mechanism after cardiac arrest in vivo. Anesthesiology 2010;112:395-405.

6 Guyton AC, Hall JE: Dominant role of the kidney in long-term regulation of arterial pressure and in hypertension: the integrated system for pressure control; in Guyton AC,Hall JE (eds): Textbook of Medical Physiology. Philadelphia, W.B. Saunders Company, 2000, pp 195-209.

7 Reckelhoff JF: Sex and sex steroids in cardiovascular-renal physiology and pathophysiology. Gend Med 2008;5(Suppl A):S1-S2.

$>8$ Cargnelli G, Rossi GP, Pessina AC, Luciani S, Debetto P, Ganten D, Peters J, Bova S: Changes of blood pressure and aortic strip contractile responses to ET-1 of heterozygous female transgenic rats, TGR(mRen2)27. Pharmacol Res 1998;37:207-211.

>9 Kasper SO, Carter CS, Ferrario CM, Ganten D, Ferder LF, Sonntag WE, Gallagher PE, Diz DI: Growth, metabolism, and blood pressure disturbances during aging in transgenic rats with altered brain renin-angiotensin systems. Physiol Genomics 2005;23:311317.

-10 Springate JE, Feld LG, Ganten D: Renal function in hypertensive rats transgenic for mouse renin gene. Am J Physiol 1994; 266:F731-F737.

- 11 Bachmann S, Peters J, Engler E, Ganten D, Mullins J: Transgenic rats carrying the mouse renin gene - morphological characterization of a low-renin hypertension model. Kidney Int 1992;41:24-36.

-12 Lee MA, Bohm M, Paul M, Bader M, Ganten U, Ganten D: Physiological characterization of the hypertensive transgenic rat TGR (mREN2)27. Am J Physiol 1996;270:E919E929.
13 Mitchell KD, Jacinto SM, Mullins JJ: Proximal tubular fluid, kidney, and plasma levels of angiotensin II in hypertensive ren-2 transgenic rats. Am J Physiol 1997;273:F246F253.

14 Dubey RK, Oparil S, Imthurn B, Jackson EK: Sex hormones and hypertension. Cardiovasc Res 2002;53:688-708.

15 Opocensky M, Dvorak P, Maly J, Kramer HJ Backer A, Kopkan L, Vernerova Z, Tesar V, Zima T, Bader M, Ganten D, Janda J, Vaneckova I: Chronic endothelin receptor blockade reduces end-organ damage independently of blood pressure effects in salt-loaded heterozygous Ren-2 transgenic rats. Physiol Res 2004;53:581-593.

16 Sullivan JC: Sex and the renin-angiotensin system: inequality between the sexes in response to RAS stimulation and inhibition. Am J Physiol Regul Integr Comp Physiol 2008;294:R1220-R1226.

$>17$ Baltatu O, Cayla C, Iliescu R, Andreev D, Jordan C, Bader M: Abolition of hypertensioninduced end-organ damage by androgen receptor blockade in transgenic rats harboring the mouse ren-2 gene. J Am Soc Nephrol 2002;13:2681-2687.

-18 Masubuchi Y, Kumai T, Uematsu A, Komoriyama K, Hirai M: Gonadectomy-induced reduction of blood pressure in adult spontaneously hypertensive rats. Acta Endocrinol (Copenh) 1982;101:154-160.

19 Rowland NE, Fregly MJ: Role of gonadal hormones in hypertension in the Dahl salt-sensitive rat. Clin Exp Hypertens A 1992;14: 367-375

20 Ouchi Y, Share L, Crofton JT, Iitake K, Brooks DP: Sex difference in the development of deoxycorticosterone-salt hypertension in the rat. Hypertension 1987;9:172-177.

21 Ganten U, Schroder G, Witt M, Zimmermann F, Ganten D, Stock G: Sexual dimorphism of blood pressure in spontaneously hypertensive rats: effects of anti-androgen treatment. J Hypertens 1989;7:721-726.

22 Reckelhoff JF, Zhang H, Granger JP: Testosterone exacerbates hypertension and reduces pressure-natriuresis in male spontaneously hypertensive rats. Hypertension 1998;31: 435-439.

23 Bachmann J, Ganten U, Zimmermann F, Mullins JJ, Stock G, Ganten D: Sexual dimorphism of blood pressure in transgenic rats TGR(mREN2)27 harboring the murine Ren-2 gene; in Sassard J (ed): Genetic Hypertension. Montrouge, John Libbey Eurotext, 1992, pp 353-355.

24 Harrap SB, Wang BZ, MacLellan DG: Renal transplantation between male and female spontaneously hypertensive rats. Hypertension 1992;19:431-434.

-25 Fischer M, Baessler A, Schunkert H: Renin angiotensin system and gender differences in the cardiovascular system. Cardiovasc Res 2002;53:672-677.
26 Zhuo J, Ohishi M, Mendelsohn FA: Roles of $\mathrm{AT}_{1}$ and $\mathrm{AT}_{2}$ receptors in the hypertensive Ren-2 gene transgenic rat kidney. Hypertension 1999;33:347-353.

$>27$ Silva-Antonialli MM, Tostes RC, Fernandes L, Fior-Chadi DR, Akamine EH, Carvalho $\mathrm{MH}$, Fortes ZB, Nigro D: A lower ratio of $\mathrm{AT}_{1} / \mathrm{AT}_{2}$ receptors of angiotensin II is found in female than in male spontaneously hypertensive rats. Cardiovasc Res 2004;62:587593.

28 Baiardi G, Macova M, Armando I, Ando H, Tyurmin D, Saavedra JM: Estrogen upregulates renal angiotensin II $\mathrm{AT}_{1}$ and $\mathrm{AT}_{2}$ receptors in the rat. Regul Pept 2005;124:7-17.

29 Nakazawa R, Tanaka M, Takahashi T, Kobayashi S, Iwamoto T: Effects of castration and testosterone administration on angiotensin II receptor mRNA expression and apoptosis-related proteins in rat urinary bladder. Endocr J 2007;54:211-219.

-30 Sampaio WO, Souza dos Santos RA, FariaSilva R, da Mata Machado LT, Schiffrin EL, Touyz RM: Angiotensin-(1-7) through receptor Mas mediates endothelial nitric oxide synthase activation via Akt-dependent pathways. Hypertension 2007;49:185-192.

-31 Husková Z, Kramer HJ, Vanourkova Z, Cervenka L: Effects of changes in sodium balance on plasma and kidney angiotensin II levels in anesthesized and conscious Ren-2 transgenic rats. J Hypertens 2006;24:517527.

32 Yanes LL, Romero DG, Iliescu R, Zhang H, Davis D, Reckelhoff JF: Postmenopausal hypertension: role of the renin-angiotensin system. Hypertension 2010;56:359-363.

- 33 Baltatu O, Cayla C, Iliescu R, Andreev D, Bader M: Abolition of end-organ damage by antiandrogen treatment in female hypertensive transgenic rats. Hypertension 2003;41: 830-833.

34 Rajagopalan S, Kurz S, Münzel T, Tarpey M, Freeman BA, Griendling KK, Harrison DG: Angiotensin II-mediated hypertension in the rat increases vascular superoxide production via membrane NADH/NADPH oxidase activation. Contribution to alterations of vasomotor tone. J Clin Invest 1996;97: 1916-1923.

-35 Kopkan L, Huskova Z, Vanourkova Z, Thumova M, Skaroupkova P, Maly J, Kramer HJ, Dvorak P, Cervenka L: Reduction of oxidative stress does not attenuate the development of angiotensin II-dependent hypertension in Ren-2 transgenic rats. Vascul Pharmacol 2009;51:175-181.

36 Xue B, Singh M, Guo F, Hay M, Johnson AK: Protective actions of estrogen on angiotensin II-induced hypertension: role of central nitric oxide. Am J Physiol Heart Circ Physiol 2009;297:H1638-H1646.
Vaněčková/Husková/Vaňourková/ Červenka 